\title{
Transverse Fetal Presentation
}

National Cancer Institute

\section{Source}

National Cancer Institute. Transverse Fetal Presentation. NCI Thesaurus. Code C92898.

A fetal position during delivery in which the alignment of the spine of the fetus is not

parallel to the mother's spine. 